\title{
Thermal motion in the multi-subunit protein apoferritin as probed by high energy resolution neutron spectroscopy
}

a ISIS Facility, UK, b TU Delft (previously Institut Laue Langevin, France)

OSIRIS / IRIS

$\Gamma_{\text {res, fwhm }}=24.5-4.0 \mu \mathrm{eV}$

$\mathrm{t}_{\max }=0.07-0.30 \mathrm{~ns}$

$\Delta \mathrm{E}= \pm 400- \pm 150 \mu \mathrm{eV}$
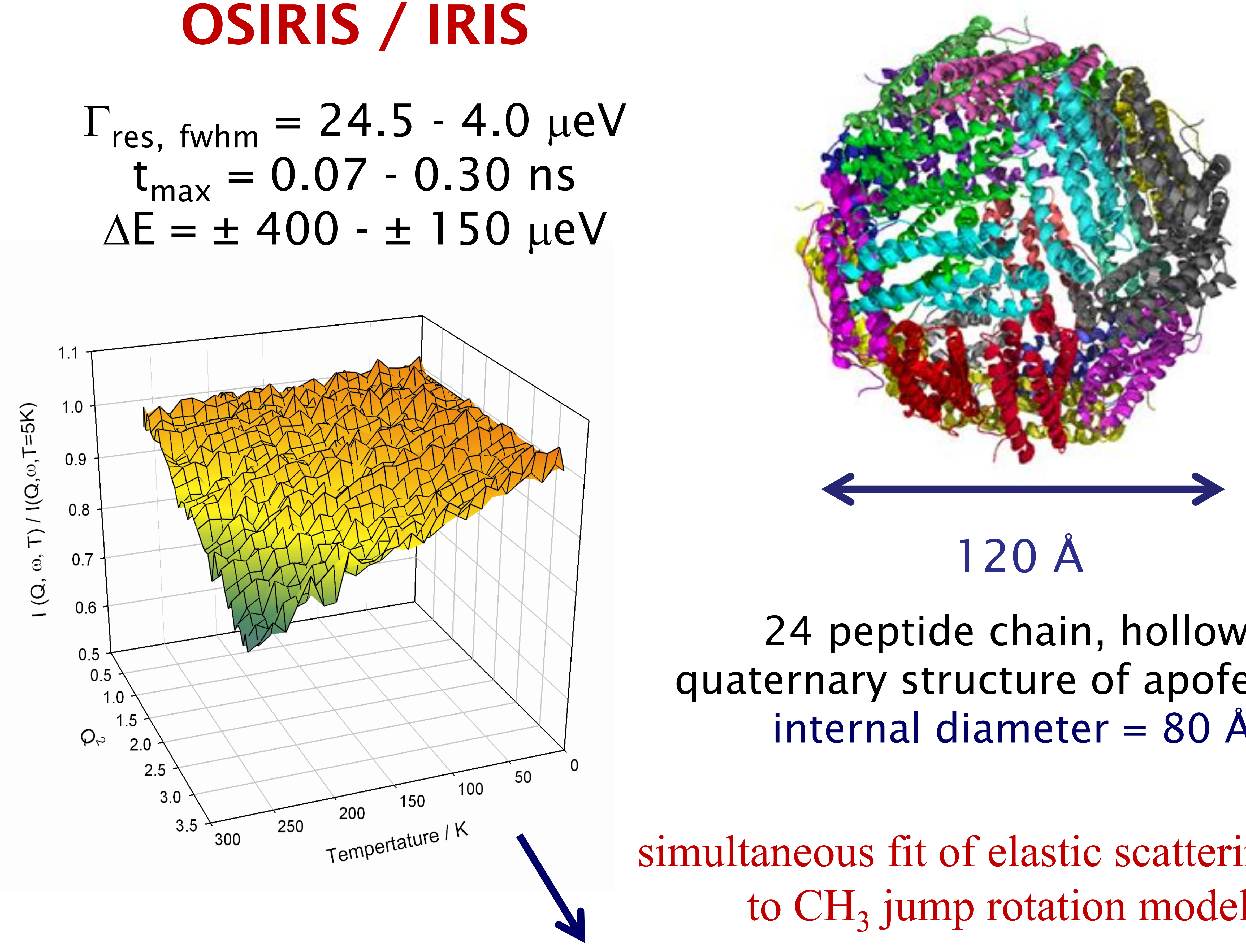

24 peptide chain, hollow, quaternary structure of apoferritin internal diameter $=80 \AA$

simultaneous fit of elastic scattering data to $\mathrm{CH}_{3}$ jump rotation model ${ }^{1}$
IN 16

$$
\begin{gathered}
\Gamma_{\text {res, fwhm }}=0.9 \mu \mathrm{eV} \\
t_{\text {max }}=2 \mathrm{~ns} \\
\Delta \mathrm{E}= \pm 14 \mu \mathrm{eV}
\end{gathered}
$$

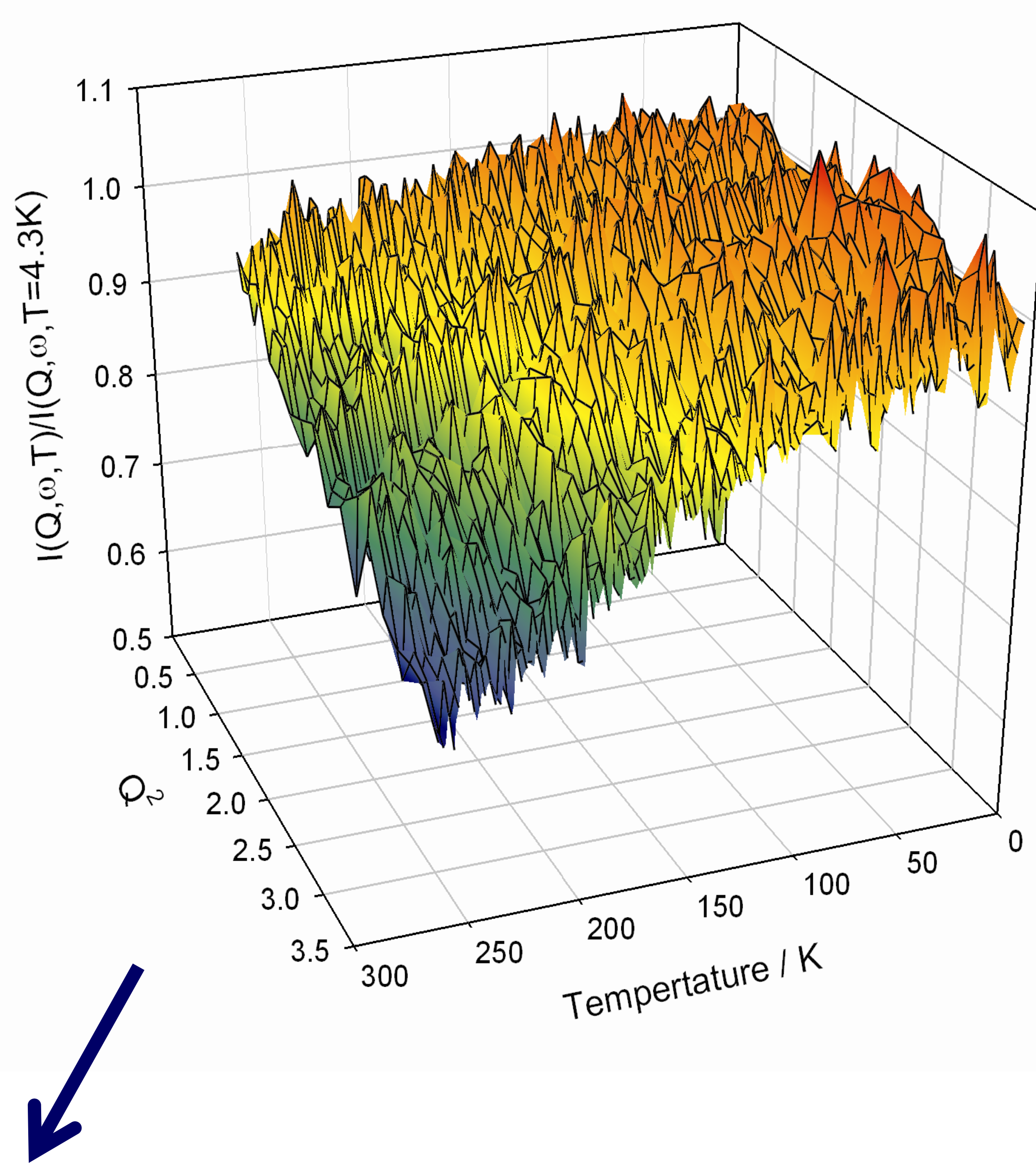
$S(Q, \omega \approx 0, T)=\exp \left(\frac{-Q^{2}<r^{2}>}{3}\right) \times\left(\left(1-p_{m}+\left(p_{m} \times A_{o}(Q)\right)\right)+\frac{2}{\pi}\left[1-\left(1-p_{m}+\left(p_{m} \times A_{o}(Q)\right)\right)\right] \times \sum g_{i} \arctan \left(\frac{\Gamma_{r e s}}{\Gamma}\right)\right)$

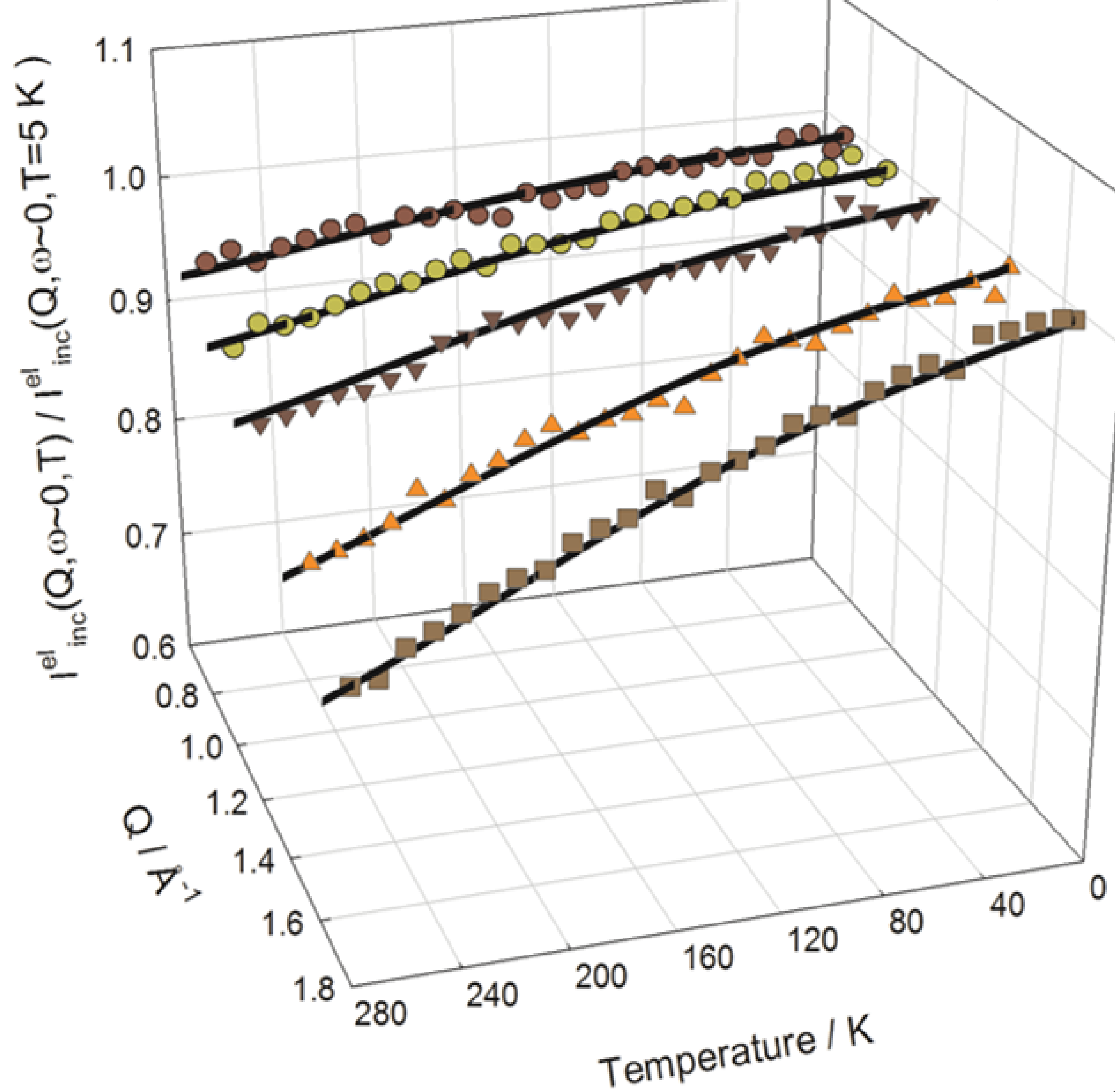

from: M.T.F Telling et al J Phys Chem B, 2008

$$
\begin{gathered}
A_{o}(Q)=\frac{1}{3}\left[1+2 j_{o}(\sqrt{3} Q a)\right] \\
\text { and } \\
\Gamma=\Gamma_{o} \exp \left(-\frac{E_{a}}{R T}\right)
\end{gathered}
$$

being validated experimentally...

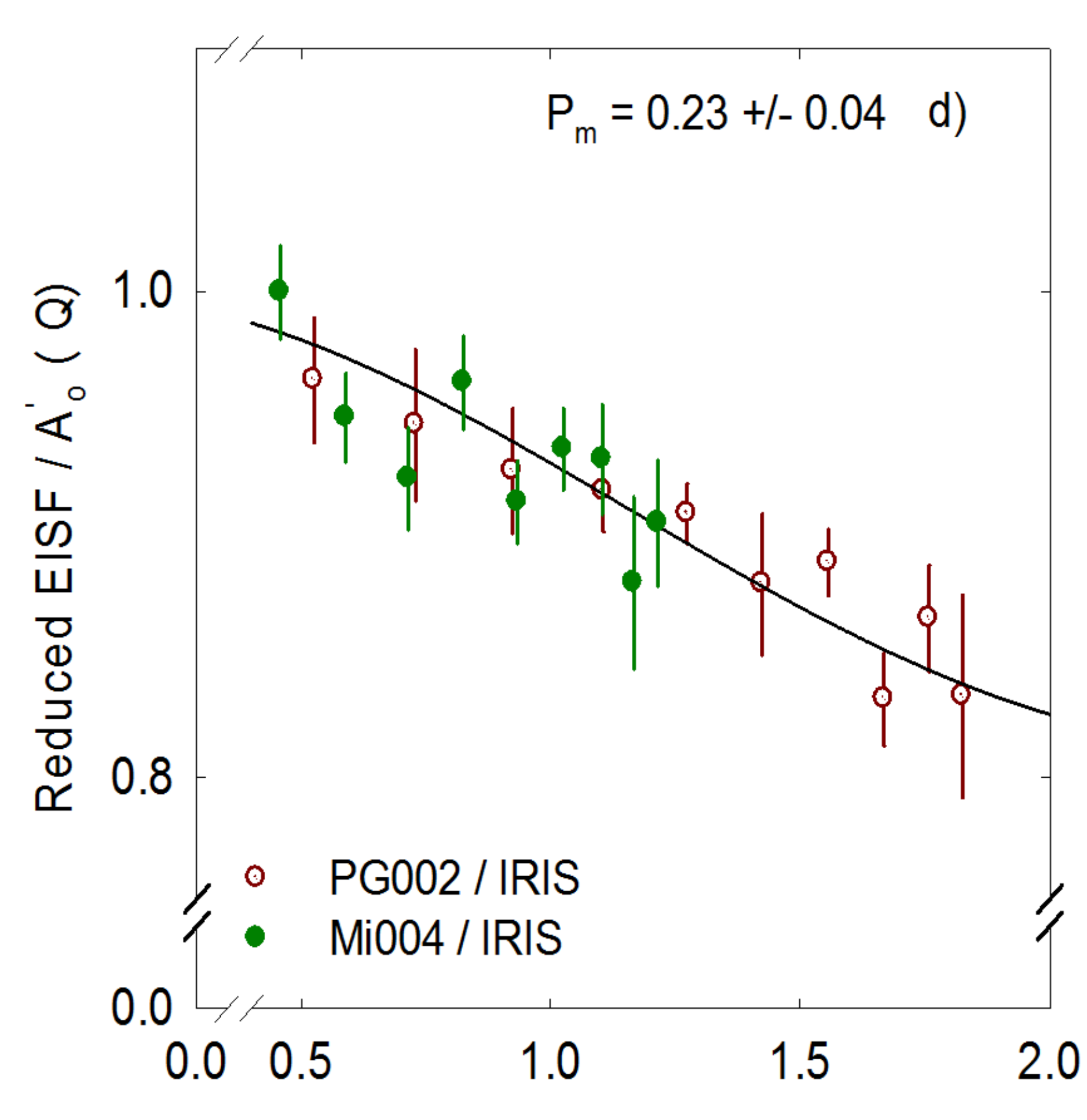

Q

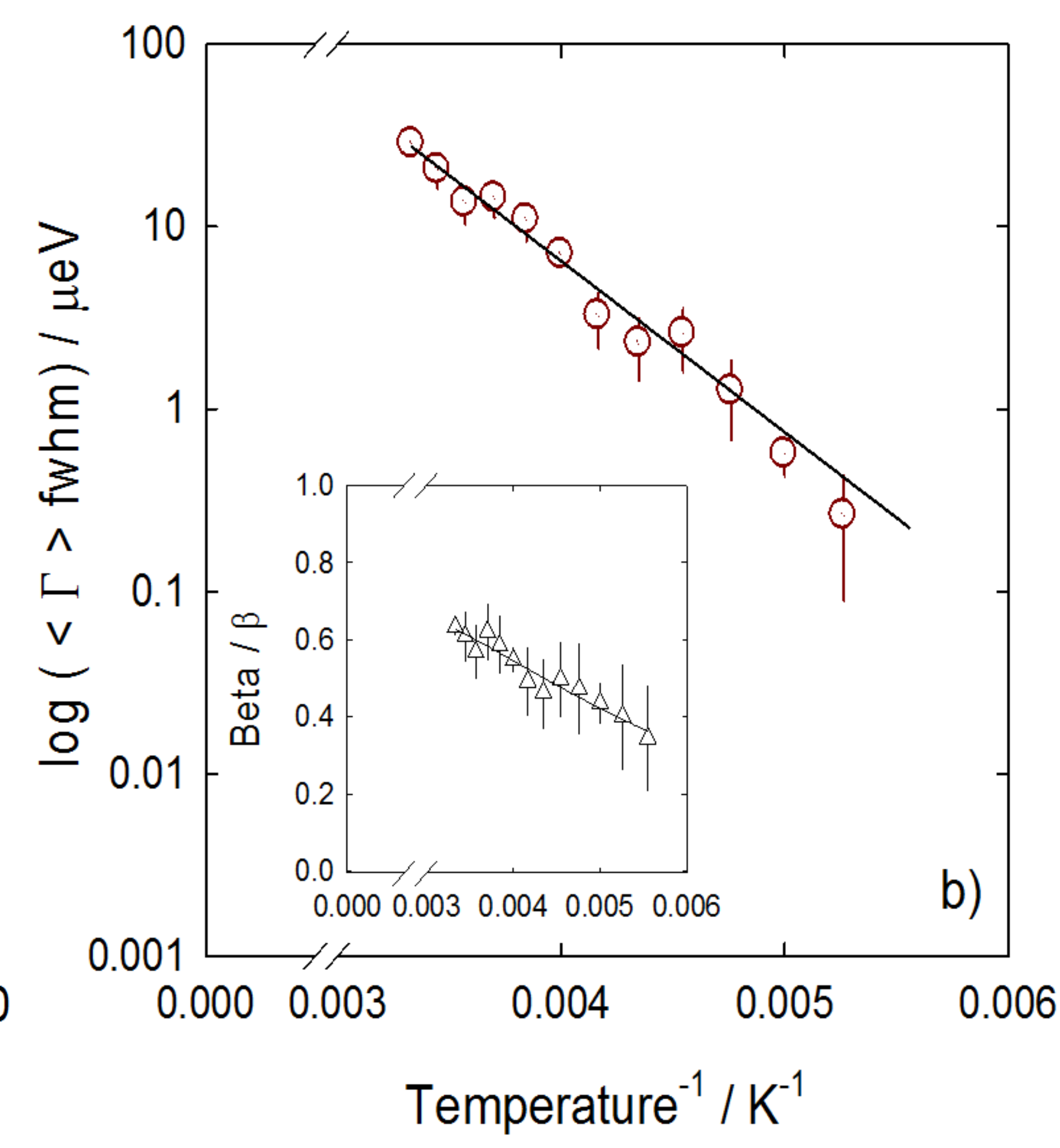

Temperature $^{-1} / \mathrm{K}^{-1}$

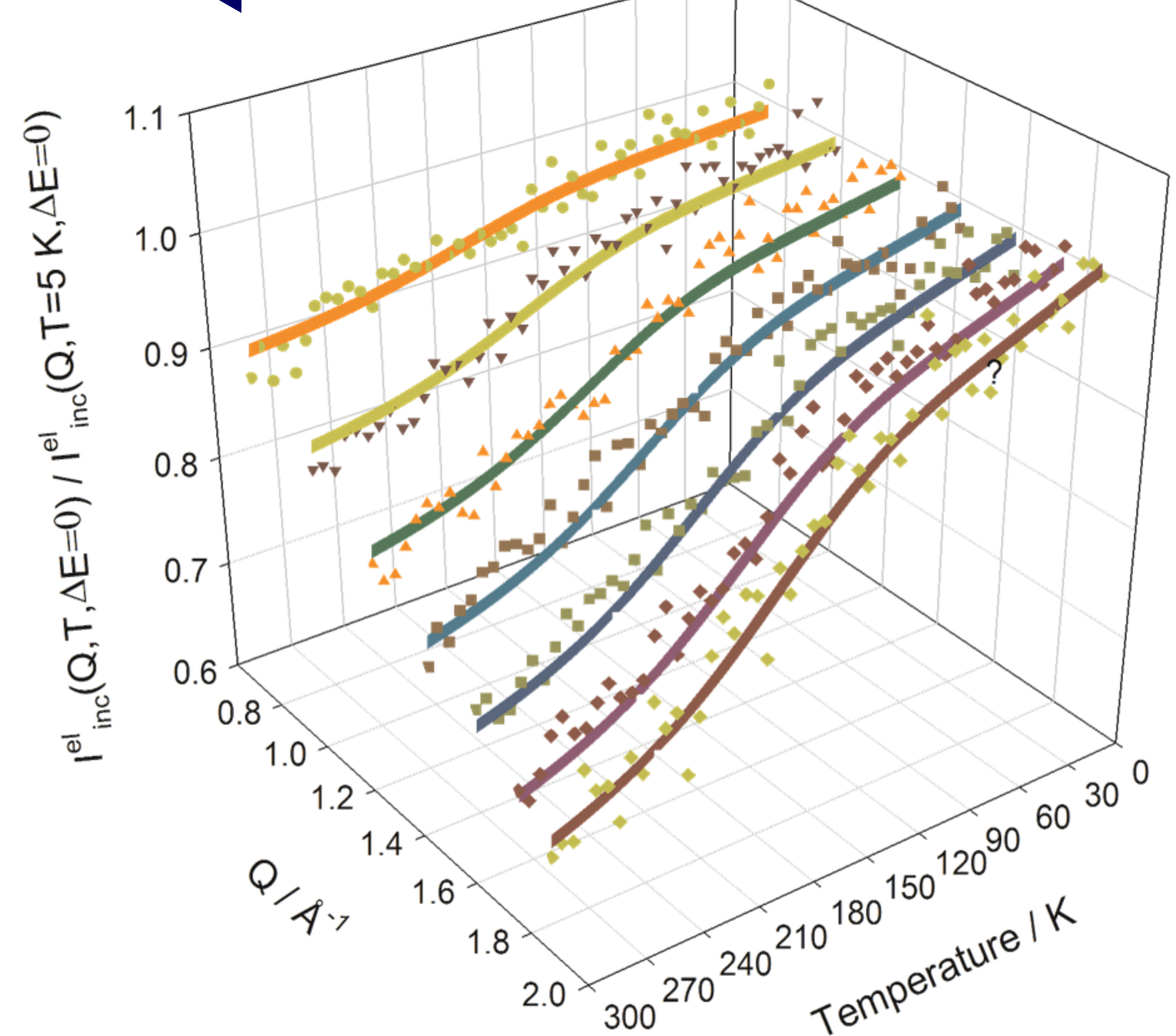

from : M.T.F Telling et al Soft Matter, 2011

Lyophilised apoferritin, above $T \sim 100 \mathrm{~K}$ and in the ps-ns time regime, exhibits a single dynamic response driven by methyl groups alone

No contribution is observed from protons associated with non- $\mathrm{CH}_{3}$ species

A distribution of $\mathrm{CH}_{3}$ activation energies is obtained in line with the environmental heterogeneity 